\title{
Induction of mesothelioma after intrapleural inoculation of F344 rats with silicon carbide whiskers or continuous ceramic filaments
}

\author{
N F Johnson, F F Hahn
}

\begin{abstract}
Objective-To find whether continuous ceramic filaments (CCFs) and silicon carbide whiskers (SiCWs), which are used in many industries as reinforcing materials in advanced ceramic composites, are carcinogenic in the intrapleural inoculation assay.
\end{abstract}

Methods-Samples of SiCWs, CCF, International Union Against Cancer crocidolite, or saline were injected into the pleural cavities of female F344/N rats to find whether the samples of $\mathrm{SiCW}$ and CCF had the potential to induce mesotheliomas after the direct application of the materials to the surface of the pleural mesothelium.

Results-Rats injected with two of the three individual samples of $\mathrm{SiCW}$ or the crocidolite had significantly reduced life spans compared with the rats treated with saline, CCFs, or the third SiCW sample. Rats treated with either of the two SiCW samples or crocidolite developed mesotheliomas. By contrast, rats treated with saline or CCF did not. The two SiCW samples that induced shortened life spans also induced a higher rate of mesothelioma $(87 \%-90 \%)$, than the crocidolite $(57 \%)$ and the third SiCW sample (23\%). Conclusion-SiCWs but not CCFs could induce mesotheliomas after intrapleural injection in rats. The difference in biological activity between the $\mathrm{SiCW}$ samples could not be explained on the basis of their physical dimensions or biological activity toward cultured cells. Results from this study indicated that SiCWs should be handled with care as they might be carcinogenic if inhaled. However, there is controversy as to whether results of intrapleural injection assays are sufficient to determine a fibre's carcinogenic activity. The results also showed that a collection of fibrous materials such as SiCWs could have considerably different biological activities despite similar physical dimensions.

(Occup Environ Med 1996;53:813-816)

Keywords: silicon carbide whiskers; mesothelioma; animal bioassay

Continuous ceramic filaments (CCFs) and silicon carbide whiskers (SiCWs) are used in the aerospace, automotive, and power generation industries as reinforcing materials in advanced ceramic composites. The SiCWs can also occur as a byproduct of silicon carbide production for the abrasive industry. ${ }^{1}$ The SiCWs are single crystal structures that can have a fine fibrous morphology similar to that of amphibole asbestos. The diameter of this fine $\mathrm{SiCW}$ is typically $\leqslant 1 \mu \mathrm{m}$. There is concern that exposure to SiCWs may be associated with pulmonary fibrosis, lung cancer, and mesothelioma, biological effects known to occur after exposure to asbestos. In vitro studies in cultured cells have shown that $\mathrm{SiCWs}$ possess similar biological activity to asbestos. ${ }^{25}$ Alteration in normal cell division may be the mechanism that induces cellular damage by these whiskers. ${ }^{6}$ Lapin et $a l^{7}$ showed that in rats a three week exposure by inhalation of 500-7500 SiCW $/ \mathrm{cm}^{3}$ results in pleural thickening and increased cellularity in the lungs. Vaughan $e t \mathrm{al}^{8}$ showed that intratracheal instillation of $\mathrm{SiCWs}$ in rats results in granulomas, as does crocidolite asbestos 18 months after exposure. Intraperitoneal injection of $\mathrm{SiCWs}$ in rats has produced equivocal results. Pott et $a l^{9}$ showed that $\mathrm{SiCW}$ produce a high incidence of abdominal mesotheliomas; Vaughan et $a l^{8}$ reported that intraperitoneal injection of SiCWs does not result in any mesotheliomas.

Continuous ceramic filaments are coarse fibres with diameters of $10-30 \mu \mathrm{m}$. In vitro studies in cultured cells have shown that CCFs do not show any adverse biological activity toward cultured cells. ${ }^{5}$ However, inhalation and intratracheal studies have not been reported for CCFs; such experiments would be impractical because of their size. Large diameter glass fibres similar to CCFs do not produce tumours after intrapleural implantation. ${ }^{10}$ Glass filaments do not produce a notable incidence of mesothelioma after intraperitoneal inoculation of high doses (up to $150 \mathrm{mg}$ ) of the material. ${ }^{9}$

The present study was conducted to find the in vivo potential of SiCWs and CCFs to induce mesothelioma. The in vivo assay chosen was intrapleural injections, which provide a useful screen to identify fibrous materials that do not produce a neoplastic response. ${ }^{11}$ This approach does not produce false positive results as can happen when intraperitoneal injections are used. ${ }^{12}$ The intrapleural assay was simpler to conduct than inhalation exposures. However, fibres that produce a positive response in the intrapleural injection assay should be further assessed by inhalation studies. " Inhalation bioassays have the advantage over injection assays in that they allow for the 
Table 1 Physical characteristics of fibre samples

\begin{tabular}{|c|c|c|c|c|c|}
\hline Sample & $\begin{array}{l}\text { Length } \\
(\mu \mathrm{m}) \\
\text { mean SEM }\end{array}$ & $\begin{array}{l}\text { Diameter } \\
(\mu \mathrm{m}) \\
\text { mean SEM }\end{array}$ & $\begin{array}{l}\text { Fibre } \\
n / m g\end{array}$ & $\begin{array}{l}\text { Specific } \\
\text { surface } \\
\text { area }\left(\mathrm{m}^{2} / \mathrm{g}\right)\end{array}$ & $\begin{array}{l}\text { Specific } \\
\text { gravity }\end{array}$ \\
\hline SiCW 1 & $4.5(0.23)$ & $0.42(0.02)$ & $7.6 \times 10^{6}$ & $3 \cdot 0$ & $3 \cdot 4$ \\
\hline $\mathrm{SiCW} 2$ & $20 \cdot 1(1 \cdot 01)$ & $0.75(0.02)$ & $1.6 \times 10^{5}$ & $1 \cdot 4$ & $3 \cdot 3$ \\
\hline SiCW 3 & $6.6(0.40)$ & $0.32(0.01)$ & $1.1 \times 10^{7}$ & $3 \cdot 6$ & $3 \cdot 2$ \\
\hline Crocidolite & $2 \cdot 1(0.31)$ & $0.12(0.01)$ & $3.6 \times 10^{4}$ & $7 \cdot 0$ & $3 \cdot 2$ \\
\hline CCF (PRD-166) & $40-100$ & 12 & ND & 1.5 & $4 \cdot 3$ \\
\hline
\end{tabular}

*Values determined approximately by light microscopy.

ND $=$ Not determined. neys, liver, heart, lungs, trachea, and larynx were removed and fixed in $10 \%$ neutral buffered formalin (NBF). The lungs were inflated with $\mathrm{NBF}$ to $30 \mathrm{~cm} \mathrm{H}_{2} \mathrm{O}$. The diaphragm and any identifiable lesion on the parietal chest wall and elsewhere in the thoracic cavity were also removed and immersed in $10 \% \mathrm{NBF}$. Fixed tissue was prepared for conventional paraffin embedding and examined by light microscopy with sections stained with haematoxylin and eosin. Only lung and thoracic lesions were routinely examined. The incidence of tumours was determined from the number of rats that developed pleural mesotheliomas. The animal survival data were analysed by the Kaplan-Meier method (SAS LIFE TEST Procedure; SAS Institute, Cary, NC) incorporating pairwise comparisons to find whether the survival of exposed rats was significantly different $(P \leqslant 0.05)$ from that of rats treated with saline. these samples. The distributions of length and diameters (table 2) were obtained from a bivariate analysis. ${ }^{5}$ Two hundred and twenty female F344/N rats, 6 to 8 weeks old, from the institute's barrier maintained colony were randomly allocated to the experimental groups (table 3). Each rat was injected intrapleurally with either saline $(0.4 \mathrm{ml})$, or $\mathrm{SiCW}$ samples 1 , 2, or $3(20 \mathrm{mg})$; International Union Against Cancer crocidolite $(20 \mathrm{mg})$; or PRD166 (a CCF) suspended in saline $(0.4 \mathrm{ml})$. The rats were killed by intraperitoneal injection of sodium pentobarbitone when moribund or when $20 \%$ of the longest surviving group of rats (injected with PRD-166) remained alive. All rats were necropsied and examined for gross lesions. The spleen, kid-

\section{Results}

The first rat died from respiratory distress at 166 days after inoculation with $\mathrm{SiCW} 2$, and the first tumour was found 273 days after inoculation with SiCW 2. Rats inoculated with SiCW 1 or 2 had the shortest life spans (figure). Rats treated with crocidolite, the positive control, had intermediate life spans compared with the rats treated with the SiCW 1 or 2 and with rats treated with saline control (figure). Rats treated with PRD-166 had life spans similar to the rats treated with saline. Rats treated with SiCW 3 had life spans between the rats treated with saline and crocidolite. The life
The fraction of rats surviving intrapleural injection varied with the different fibre inoculations. Saline and PRD-166 produced a similar response, which was different from that of crocidolite, the positive control. SiCWs 1 and 2 showed a similar response, also different from crocidolite.
Table 2 Length/diameter distribution (\%) for SiCW samples

\begin{tabular}{|c|c|c|c|c|c|c|c|c|}
\hline $\begin{array}{l}\text { Diameter }(\mu \mathrm{m}) \text { : } \\
\text { SiCW } 1 \\
\text { SiCW } 2 \\
\text { SiCW } 3 \\
\text { Length }(\mu \mathrm{m}) \text { : } \\
\text { SiCW } 1 \\
\text { SiCW } 2 \\
\text { SiCW } 3\end{array}$ & $\begin{array}{l}0-0 \cdot 9 \\
4 \cdot 1 \\
- \\
9 \cdot 29 \\
0-1 \cdot 9 \\
25 \cdot 2 \\
\overline{21} \cdot 26\end{array}$ & $\begin{array}{l}0 \cdot 1-0 \cdot 19 \\
17 \cdot 0 \\
1 \cdot 7 \\
23 \cdot 36 \\
2 \cdot 0-3 \cdot 9 \\
32 \cdot 2 \\
\overline{30} \cdot 24\end{array}$ & $\begin{array}{c}0 \cdot 2-0 \cdot 29 \\
26 \cdot 2 \\
8 \cdot 1 \\
17 \cdot 07 \\
4 \cdot 0-5 \cdot 9 \\
17 \cdot 9 \\
7 \cdot 6 \\
12 \cdot 21\end{array}$ & $\begin{array}{l}0 \cdot 3-0 \cdot 39 \\
16 \cdot 7 \\
15 \cdot 2 \\
21 \cdot 57 \\
6 \cdot 0-7 \cdot 9 \\
7 \cdot 9 \\
8 \cdot 1 \\
8 \cdot 70\end{array}$ & $\begin{array}{l}0 \cdot 4-0 \cdot 59 \\
14 \cdot 8 \\
18 \cdot 5 \\
21 \cdot 49 \\
8 \cdot 0-9 \cdot 9 \\
8 \cdot 0 \\
9 \cdot 5 \\
8 \cdot 69\end{array}$ & $\begin{array}{l}0 \cdot 6-0 \cdot 79 \\
10 \cdot 1 \\
18 \cdot 1 \\
6 \cdot 00 \\
10 \cdot 0-14 \cdot 9 \\
5 \cdot 5 \\
24 \cdot 2 \\
10 \cdot 18\end{array}$ & $\begin{array}{c}0 \cdot 8-0 \cdot 99 \\
6 \cdot 2 \\
13 \cdot 2 \\
0 \cdot 60 \\
>15 \cdot 0 \\
3 \cdot 0 \\
46 \cdot 9 \\
8 \cdot 70\end{array}$ & $\begin{array}{c}>1 \cdot 0 \\
4 \cdot 6 \\
25 \cdot 4 \\
0.60\end{array}$ \\
\hline
\end{tabular}

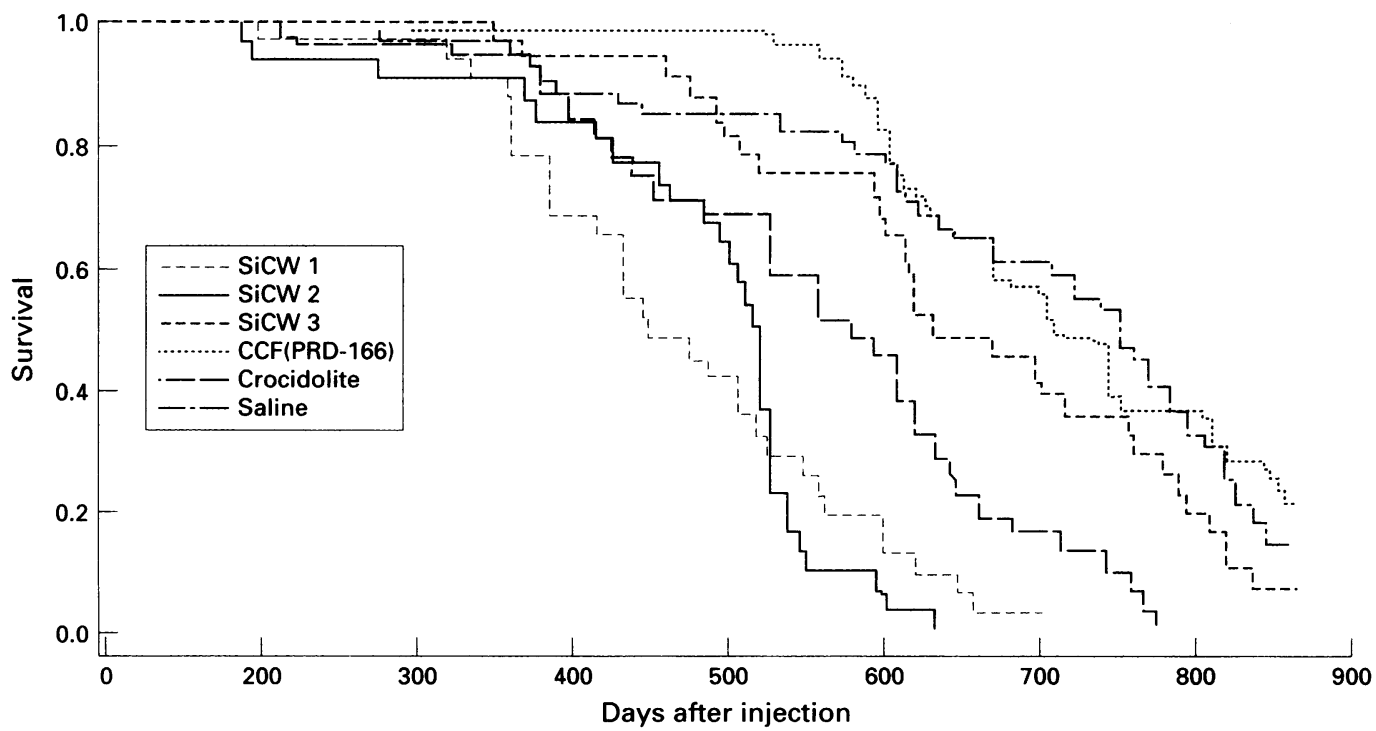


Table 3 Occurrence of pleural mesotheliomas by treatment group

\begin{tabular}{|c|c|c|c|c|c|c|}
\hline Sample & $\underset{n}{\text { Animals }}$ & $\begin{array}{l}\text { Animals } \\
\text { with } \\
\text { mesothelioma }\end{array}$ & $\begin{array}{l}\text { Animals } \\
\text { with } \\
\text { mesothelioma (\%) }\end{array}$ & $\begin{array}{l}\text { Time of } \\
\text { first tumour }\end{array}$ & $\begin{array}{l}\text { Mean time } \\
\text { to tumour } \\
\text { (days (SEM)) }\end{array}$ & $\begin{array}{l}\text { Median survival } \\
\text { time } \\
\text { (days after } \\
\text { injection (SEM))† }\end{array}$ \\
\hline $\begin{array}{l}\text { Saline } \\
\text { CCF (PRD-166) } \\
\text { SiCW } 1 \\
\text { SiCW } 2 \\
\text { SiCW } 3 \\
\text { Crocidolite }\end{array}$ & $\begin{array}{l}50 \\
50 \\
30 \\
30 \\
30 \\
30\end{array}$ & $\begin{array}{r}0 \\
0 \\
27 \\
26 \\
7 \\
17\end{array}$ & $\begin{array}{r}0 \\
0 \\
90 \\
87 \\
23 \\
57\end{array}$ & $\begin{array}{l}- \\
\overline{320} \\
273 \\
349 \\
416\end{array}$ & $\begin{array}{l}- \\
\overline{465}(25) \\
499(15) \\
651(30) \\
608(23)\end{array}$ & $\begin{array}{l}753(25) \\
708(18) \\
453(21)^{\star} \\
519(20)^{\star} \\
635(26) \\
548(24)^{\star}\end{array}$ \\
\hline
\end{tabular}

spans of the rats treated with SiCW 1 or 2 and crocidolite were significantly shorter than those of the animals treated with saline. The life spans of the rats treated with PRD-166 or SiCW 3 were not significantly different from those of the rats treated with saline.

Histopathological examination of the thoracic contents from all rats showed that the three samples of $\mathrm{SiCW}$ varied in their ability to induce pleural mesotheliomas (table 3). The SiCWs 1 and 2 resulted in $90 \%$ and $87 \%$ respectively, of the treated rats developing pleural mesothelioma. Twenty seven per cent of the rats treated with $\mathrm{SiCW} 3$ and $57 \%$ of those treated with the positive control (crocidolite) developed pleural mesotheliomas. No tumours were identified in the animals treated with saline or PRD-166 (table 3). The tumours identified, with one exception, were sarcomatous in appearance and, in all but one case, involved the visceral pleura. Fibres were found in sections from all treatment groups except those animals treated with saline or PRD-166.

\section{Discussion}

These results showed that SiCWs could induce mesotheliomas when introduced into the pleural cavity, and that two SiCW samples were at least as carcinogenic as amphibole asbestos when given this way. The notable responses with two of the three $\mathrm{SiCW}$ samples indicated that $\mathrm{SiCW}$ should be handled with care and treated as a suspected carcinogen until the results of long term inhalation studies are available. The results of this study also showed that CCFs (PRD-166) did not induce mesotheliomas when injected into the pleural cavity of rats. This information combined with the negative in vitro data ${ }^{5}$ and the fact that the diameter of this material precludes inhalation showed that exposure to CCFs should not represent a significant health hazard. Shannon et $a l^{13}$ showed that the mortality of workers with glass filament is below that expected, and deaths due to lung cancer did not increase significantly. However, the extremely low airborne concentrations encountered in a continuous glass filament factory may preclude the ability of any workplace epidemiological study to investigate the potential risk of respiratory cancer from continuous glass filaments. ${ }^{14}$

The amount of published information providing details about the toxicological properties of SiCWs and CCFs is limited. The results of the present intrapleural study support results from previous animal studies. Three studies have been reported involving $\mathrm{SiCW}$ implanted into the pleural cavity ${ }^{10}$ and injected into the peritoneal cavity. ${ }^{8}{ }^{9}$ Pott $e t ~ a l^{9}$ gave an unequivocal positive result although many of the animals died of an infectious lung disease. Also, the intraperitoneal injection may be overly sensitive to fibres and particles such as silica. ${ }^{11}$ By contrast, the study of Vaughan et $a l^{8}$ reported that intraperitoneal injection of SiCWs does not result in the development of mesotheliomas. However, Vaughan et $a l^{8} \mathrm{did}$ not use a positive control such as crocidolite in their studies. Stanton et $a l^{10}$ reported a high incidence of pleural tumours in rats implanted with $\mathrm{SiCWs}$. In a subchronic inhalation study in rats, pleural thickening and increased cellularity of the lung parenchyma have been found at 26 weeks after a 13 week exposure to a high concentration of SiCW (6 h/day, 5 days/week, 500-7500 fibres $\left./ \mathrm{cm}^{3}\right) .{ }^{7}$ The fibres in this study had an average diameter of $0.58 \mu \mathrm{m}$ and average length of $4.7 \mu \mathrm{m}$. The relevance of the pleural thickening is not known; however, it has been reported to occur after exposure to erionite in rats ${ }^{15}$ and refractory ceramic fibres in hamsters. ${ }^{16}$ In studies with erionite and refractory ceramic fibres, high incidences of mesotheliomas have been reported. ${ }^{16}{ }^{17}$

Information on human exposures to $\mathrm{SiCWs}$ is also sparse. Exposure to SiCWs has been reported in workers exposed to silicon carbide in the abrasive industry as illustrated by the presence of SiCWs in lung tissue ${ }^{1819}$ and in the working environment. ${ }^{2021}$ Whether these fibres contribute to the pneumoconiosis associated with workers involved in silicon carbide production is unknown. ${ }^{22} \mathrm{~A}$ similar situation has been reported in the hard metal industry where the presence of tungsten oxide whiskers may contribute to the pneumoconiosis noted in some workers employed in the production of hard metal. ${ }^{23}$

In the present study, the differences in the biological activity of the three SiCW samples could not be explained by differences in fibre morphology. The fibre length/diameter distributions were dissimilar. The SiCW 2 contained a disproportionate number of long, thin fibres, which are thought to be important in fibre carcinogenesis ${ }^{10}$ and this sample was highly carcinogenic. However, SiCW 1 had a similar carcinogenic potency as SiCW 2 but had a lower fraction of fibres $\geqslant 20 \mu \mathrm{m}$ in length than $\mathrm{SiCW} 3$, which was significantly less carcinogenic than either SiCW 1 or 2 . The 
difference in reactivity could not be explained on a fibre number basis as SiCW 3 (the least reactive $\mathrm{SiCW}$ ) contained the highest number of fibres in the inoculum. Although fibre dimensions are a critical factor for carcinogenesis these results indicate that other aspects of a fibre must also be important. Surface chemistry may be an important factor in the development of tumours; however, the ability of SiCWs to induce hydroxyl radicals in vitro is limited compared with the natural crystalline minerals. ${ }^{2+}$ In the case of SiCWs, surface chemistry may have a limited influence on their carcinogenic potency. The physical surface of the SiCW samples was different and it is unclear whether this might contribute to their divergent biological activity.

The in vitro activity of the three SiCW samples did not indicate the in vivo biological activity. In two cell lines (LEC and A549) SiCW 1 was the least toxic whereas SiCW 3 was the most toxic; however, SiCW 2 was the most toxic towards rat alveolar macrophages and rat tracheal epithelial cells. ${ }^{5}$ These results showed that physicochemical characterisation and in vitro cytotoxicity studies cannot necessarily predict accurate in vivo activity.

The technical help of RJ Jaramillo, KM McLeod, DC Esparza and the staff of the institute's small animal care unit, as well as and the staff of the institute's small animal care unit, as well as
necropsy and histology personnel is gratefully acknowledged. necropsy and histology personnel is gratefully acknowledged. analysis. This research was supported by the Office of Industrial Programs and the Office of Health and Environmental Research, US Department of Energy, under Contract DE-AC04-76EV01013 in facilities fully accredited by the American Association for the Accreditation of Laboratory Animal Care.

1 Hayashi H, Kajita A. Silicon carbide in lung tissue of a worker in the abrasive industry. Am f Ind Mid 1988 14:145-55.

2 Lipkin LE. Cellular effects of asbestos and other fibers: correlations with in vivo induction of pleural sarcoma Euviron Health Perspect 1980;34:91-102.

3 Birchall JD, Stanley DR, Mockford MJ, Pigott GH, Pinto PJ. Toxicity of silicon carbide whiskers. $7 \mathrm{Mat} S_{c i} L_{c t t}$ $1988 ; 7: 350-52$

4 Vaughan GL, Jordan J, Karr S. The toxicity, in vitro, of silicon carbide whiskers. Environ Res 1991;56:57 67.

5 Johnson NF, Hoover MD, Thomassen DG, Cheng YS Dalley A, Brooks AL. In vitro activity of silicon carbide whiskers in comparison to other industrial fibers using four cell culture systems. Am F Ind Med 1992;21:807-23

6 Brooks AL, Mitchell CE, Loyd T, McDonald KE, Johnson $\mathrm{NF}$. Genotoxic effects of silicon carbide whiskers. In
Vitro Toxicol 1992;5:51 8

7 Lapin CA, Graig DK, Valerio MG, McCandless JB, Bogoroch R. A subchronic inhalation study in rats exposed to silicon carbide whiskers. Fundam Appl Toxicol 1991;16:128-46.

8 Vaughan GL, Trently SA, Wilson RB. Pulmonary response, in vivo, to silicon carbide whiskers. Environ Res 1993;63:191-201.

9 Pott F, Roller M, Rippe RM, Germann P-G, Bellman B. Tumors by the intraperitoneal and intrapleural routes and their significance for the classification of mineral fibers. In: Brown RC, Hoskins JA, Johnson NF, eds. fibers. In: Brown RC, Hoskins JA, Johnson NF, eds. Mechunisms in fibre
Press, 1992:547-65.

10 Stanton MF, Layard M, Tegeris A, Miller M, May M, Morgan E, Smith A. Relation of particle dimension to carcinogenicity in amphibole asbestos and other fibrous materials. F Natl Cancer Inst 1981;67:965-75.

11 Johnson NF. The limitations of inhalation, intratracheal, and intracoelomic routes of administration for identifying hazardous fibrous materials. In: D Warheit, ed. Fiber toxicology. New York: Academic Press, 1993:43-72.

12 Johnson NF. An overview of animal models for assessing synthetic vitreous fibers (SVFs) safety. Rig Toxicol Synthetic vitreous fibers
Pharmacol 1994;20:S7-21

13 Shannon HS, Jamieson E, Julian JA, Muir DCF. Mortality of glass filament textile workers. Br F Ind Med 1990;47 5336.

14 Davies L, Cherrie JW. Airborne fibre concentrations in a glass continuous filament factory. Ann Occup $H_{y}$ : 1992;36:609-27.

15 Johnson NF, Wagner JC. Response of rat lung to inhaled erionite fibers. In: AP Wehner, D Felton, eds. Biological interaction of inhaled mineral fibers and cigarette smoke. Columbus, OH: Battelle Press, 1989:325-45.

16 Hesterberg TW, Mast R, McConnell EE, Chevalier J, Bernstein DM, Bunn WB, Anderson R. Chronic inhalation toxicity of refractory ceramic fibers in Syrian hamsters. In: Brown RC, Hoskins JA, Johnson NF, eds. Mechanisms in fibre carcinogenesis. New York: Plenum Press, 1992:539-46.

17 Wagner JC, Skidmore JW, Hill RJ, Griftiths DM. Erionite exposure and mesotheliomas in rats. Br. 7 Cancer 1985 51:727 30 .

18 Funahashi A, Schulter DP, Pintar K, Siegesmund KA, Mandel GS, Mandel NS. Pneumoconiosis in workers exposed to silicon carbide. Am Rec Respir Dis 1984; 129:635 40.

19 Masse S, Begin R, Cantin A. Pathology of silicon carbide pneumoconiosis. Mod Pathol 1988;1:1048.

20 Dufresne A, Perrault G, Sébastien P, Adnot A, Baril M Morphology and surface characteristics of particulates from silicon carbide industries. Am Ind Hyg Assoc 7 1987;48:718-29.

21 Bye E, Eduard W, Gjonnes J, Sorbroden E. Occurrence of airborne silicon carbide fibers during industrial production of silicon carbide. Scand 7 Work Environ Hialth $1985 ; 11: 1115$.

22 Marcer G, Bernardi G; Bartolucci GB, Mastrangelo G, Belluco V, Composampiero A, Saia B. Pulmonary impairment in workers exposed to silicon carbide. Br f Ind Mid 1992;49:489-93.

23 Sahle W, Laszlo I, Krantz S, Christensson B. Airborne tungsten oxide whiskers in a hard-metal industry. Preliminary findings. Ann Occup Hyg 1994;38:37-44

24 Johnson NF, Maples KR. Fiber-induced hydroxyl radical formation and DNA damage. In: MC Jaurand, JMC Davis, eds. The effects of mineral dust on cells. Berlin Springer-Verlag, 1994:23 37. (NATO ASI Series. Vo H85.) 